\title{
Scribe Hero: An Online Teaching and Learning Approach for the Development of Writing Skills in the Undergraduate Classroom
}

\author{
Kimberly Francis, Jodie Salter, Lucia Costanzo, and Serge Desmarais \\ University of Guelph \\ Meagan Troop \\ Sheridan College \\ Rosheeka Parahoo \\ Western University
}

\begin{abstract}
This study examined whether writing skills could be taught to post-secondary students via online learning modules and what student perceptions of such a learning process were like. A pilot study of the modules - called Scribe Hero - was conducted in the Fall of 2017. Statistical analysis of quantitative data reveals an improvement in student writing skills following their engagement with the online learning modules. Thematic analysis of qualitative data revealed that the students were engaged by the experience, finding it educational and refreshingly different from in-class options. The feedback also suggested that user-friendly technology, tone of the online environment, incentivising meaningful feedback, and maintaining a sense of direct applicability of content are essential to capitalising on this teaching and learning methodology. Overall, the findings of this small-scale research study support further development of this technology while also offering lessons that can be transferred to other contexts for teaching writing.
\end{abstract}

Keywords:

Francis, K., Troop, M., Salter, J., Parahoo, R., Costanzo, L., \& Desmarais, S. (2019). Scribe hero: An online teaching and learning approach for the development of writing skills in the undergraduate classroom. Online Learning, 23(2), 217-234.

doi:10.24059/olj.v23i2.1531

\section{Author Contact}

Kimberly Francis - kfranc02@uoguelph.ca; Meagan Troop - meagan.troop@sheridancollege.ca; Jodie Salter-jsalter@uoguelph.ca; Rosheeka Parahoo - rparahoo@uwo.ca;

Lucia Costanzo-1costanz@uoguelph.ca; Serge Desmarais - s.desmarais@exec.uoguelph.ca 


\section{Scribe Hero: An Online Teaching and Learning Approach for the Development of Writing Skills in the Undergraduate Classroom}

Students' ability to write academically has been identified as a bottleneck (Pace, 2017)an area in which students consistently struggle or "get stuck"-in several undergraduate courses. This research study was borne out of a ubiquitous need to teach writing skills explicitly in an effective and timely way in the first-year undergraduate classroom. Many first-year, introductorylevel courses tend to attract students from a variety of disciplines across a given campus - students enrolled include elective seekers and the curious alike. The specific course which served as the initial inspiration for this project was the first-year music history course, "Amadeus to Zeppelin: Music and Culture I," at the University of Guelph. Students in this course are required to learn foundational writing and research skills, which can be particularly burdensome for instructors. Finding ways to effectively integrate and to explicitly teach these skills in an engaging manner is a perennial issue, making it a prime venue for exploring the efficacy of a blended approach that includes online learning modules. Though we initially developed Scribe Hero for this music course, after opening use of the modules to professors outside the field of music, the pilot study soon included classes from ten different subject areas, rendering our first study of Scribe Hero a multidisciplinary endeavour.

Online learning and teaching have played a significant role in shifting the pedagogical, economic, and social landscape of post-secondary education in Canada. According to a 2017 survey, almost all Canadian colleges and universities offer online courses and most of these institutions have been doing so for fifteen years or more (Bates, 2017). With the rapid development of educational technologies, and an increasing demand for multiple pathways toward degree and diploma completion, teaching and learning online offers a viable solution for accommodating a diverse community of learners. More specifically, Heuer and King (2004) point to the unique attributes that online learning offers, such as "flexibility — anytime, anyplace - along with time for reflection and learners' anonymity." Drawing on these unique attributes, we set out to provide students with an online learning experience to develop their writing skills.

Scribe Hero is just that, a series of modules designed to enhance the development of writing skills in the undergraduate classroom. To explore the efficacy of our approach, and in the interest of continued development, we launched a pilot study intended to capture the learners' experience when engaging with Scribe Hero. The three central research questions we explored were the following:

1. In what ways, if any, did quantitative test scores change following the introduction of online learning modules?

2. What roles did feedback play in the online learner experience?

3. What were students' perceptions of the online learning module experience?

\section{Review of Literature}

\section{Designing the Online Experience}

In designing the Scribe Hero online modules, a strong pedagogical driver was creating a personalized learning experience for students. Recent research indicates that student engagement in multimedia learning is an approach that motivates undergraduate learners (Burke, 2010; de Freitas, 2012; Reimers, 2008; Zeni, White, Wilson, \& Troop, 2018). Thus, Scribe Hero employed 
a mixed media approach, combining tasks that took place both within and were external to the online environment. In addition, numerous studies reveal that a sense of agency and autonomy in online learning is essential for student engagement (All, Castellar \& Looy, 2016; Barab, Peetyjohn, Gresalfi, Volk \& Solomou, 2012; Dalton 2000; de Freitas, 2012; Jalongo, 2007). Further, students are more engaged when a narrative or immersive element is present in a virtual environment (Asbell-Clarke \& Edwards, 2016; Barab, Arici \& Jackson, 2005; Hamari, Shernoff, Rowe, Coller, 2016). With these considerations in mind, the Scribe Hero modules were designed to reinforce what researchers have identified as the three key features of motivating online experiences: interactivity, agency, and engagement. (All et al., 2015; Erhel \& Jamet, 2013; Hamari, et al. 2016; Qian \& Clark, 2016; Rigby \& Ryan, 2007)

Beyond the overall look, feel, and structure of online learning modules, we applied outcome-based language acquisition principles (Carter, 2003, 2007; Condon \& Kelley-Riley, 2004; Gammill, 2006). In alignment with the developed learning outcomes, we established paraprofessional exercises - assignments that mimic job-based writing scenarios - throughout the modules. We based this design component upon research that showed that paraprofessional contexts frequently yield a higher level of student engagement than is normally generated through the use of more traditional assignment structures such as essays or stand-alone, abstract writing modules (Antonius, Brown, Todman \& Safran, 2007; Gresty \& Edwards-Jones, 2012). Similarly, interactive writing projects tend to encourage students to become more invested in the content and therefore assist in developing their own research interests (Antonius et al., 2007; Zhao \& Wardeska, 2011). The incorporation of these elements into the pedagogical structure is also in keeping with best practices in online tutorial design (Blummer \& Kritskaya, 2009; Erhel \& Jamet, 2013; All et al., 2016; Hamari et al., 2016).

Additional design elements were drawn from the principles of strategy instruction (Graham, 2006). Strategy instruction is a cognitive approach to learning writing skills whereby writing is broken down into explicitly identified components, which are analysed and practiced, thus leading to familiarity and expert performance. Strategy instruction has been shown to have a significant impact on the quality of post-secondary student writing (Graham, 2006). Similarly, evidence suggests that small, "nested" assignments provide systematic support for students working toward larger, more complex writing projects (Bean, 2011). All these ideas were incorporated into the design of the Scribe Hero modules. For the learning outcomes of the four modules of Scribe Hero, see Table 1: 
Table 1

Learning Outcomes, Scribe Hero

Module

Learning Outcomes

\begin{tabular}{|c|c|}
\hline One: Planning/Pre-Writing & $\begin{array}{l}\text { - Identify how to approach an assignment through } \\
\text { brainstorming and pre-writing stages } \\
\text { - Describe and demonstrate the difference between } \\
\text { analytical and descriptive prose }\end{array}$ \\
\hline Two: Writing & $\begin{array}{l}\text { Confidently apply verbs (how to choose good verbs), } \\
\text { positive vs. negative constructs, and known-to-new tips for } \\
\text { increasing clarity and flow } \\
\text { - Construct effective paragraphs through a series of writing } \\
\text { exercises }\end{array}$ \\
\hline $\begin{array}{l}\text { Three: Citation - } \\
\text { discipline specific }\end{array}$ & $\begin{array}{l}\text { Explore the ethics of scholarly citation to interpret } \\
\text { scenarios dealing with plagiarism and academic } \\
\text { misconduct } \\
\text { - Identify how to cite materials (either through quoting or } \\
\text { paraphrasing) in a discipline-specific manner } \\
\text { - Explain what a style guide is and how to use it effectively } \\
\text { and in a discipline-specific manner }\end{array}$ \\
\hline Four: Grammar & $\begin{array}{l}\text { - Recognize that grammar is a secondary tool } \\
\text { - Evaluate the grammar errors after the first stage of writing } \\
\text { - Locate and correctly construct certain clauses and } \\
\text { fragments } \\
\text { - Develop different sentence types } \\
\text { - Identify and employ various types of punctuation } \\
\text { - Locate and correctly employ modifiers }\end{array}$ \\
\hline
\end{tabular}

\section{Building the Online Modules}

The Scribe Hero modules were built with Adobe Captivate software. Students chose to engage with the modules as one of three different characters, drawn from music-based professions: (1) a band publicist; (2) an arts magazine intern; or (3) an arts website music critic. The modules employed cut-screen videos to present a paraprofessional scenario and instructional videos with embedded, on-screen text to introduce specific skills and concepts. These videos were built using the shareware Powtoons. Links to these videos were then embedded into the Captivate shell, and the videos streamed from YouTube to prevent buffering due to the large sizes of the video files. Learning interactions and games drawn from the Captivate library were built to reinforce content taught in the instructional videos. Students were also provided with a "notebook," which was a resource external to the online environment that contained fill-in-the-blank notes that students could complete while watching the instructional videos. These notebooks also encouraged multiple learning modalities. Students had the choice to work with this notebook either as a form-fillable PDF or to print it off and work with it as a hard copy. Instructors were given the option of whether to collect the notebook from students to provide feedback. 
The notebook was essential to executing certain online activities because it allowed for the housing of larger text examples, such as full paragraphs when discussing proper paragraph structure. Embedding these larger paragraphs into the online environment itself would have required the use of unreadable fonts or scrolling functionality that exceeded the capabilities of the Captivate environment. The notebook resolved these issues. It was also intended to serve as a reference tool that students could keep and return to after they had finished with Scribe Hero.

Instructional material was organized by using the same methodology for each module. First, students entered the online environment through their Learning Management System (LMS). There, they encountered scenarios via cut-screen videos. These videos prompted students to learn specific writing skills so as to be able to execute the paraprofessional tasks with which the video presented them. For example, students who chose the arts magazine intern narrative were told of a colleague caught and fired for plagiarizing. They were then challenged to improve their own knowledge of citation skills to avoid similar errors. This setup was followed by videos about the ethics and mechanics of citation. Students then completed activities and exercises that reinforced citation skills. At the end of each module, students were prompted to exit the online environment to complete a summary exercise. This exercise, found in their notebook, required them to synthesize and transfer the skills taught in the online modules to execute an error-detection or composition task. Upon completing this task, students were prompted to upload an image of their work to the LMS for evaluation by their professor either by taking a picture of their work (hardcopy of the notebook) and uploading it to the LMS or by taking a screen shot (digital copy of the notebook) and uploading it to the LMS.

All module elements were designed with accessibility concerns in mind. Students could engage with the content on any digital device (phone, tablet, or personal computer), although they were encouraged to use personal computers because functionality decreased when students accessed the material on other devices. All materials in the modules were tested for contrast to optimize visual accessibility, and all material presented in the videos contained both text and audio to optimize accessibility and to speak to a variety of learning modalities. The team also created additional transcripts for videos that were available for download when closed captioning was not also available. Accessibility was somewhat limited with the learning activities provided by Captivate, so the team developed alternate, fully accessible versions of each module. An entirely accessible version for Module 1 was ready for use when the beta project rolled out, providing enough lead time to develop subsequent modules should someone request the remainder of the game in an accessible format. The team has identified accessibility as an area that can and will be improved upon in future development.

When exported as HTML5 files, the Adobe Captivate shell was quite fragile and prone to freezing or failing, especially when embedded in the LMS. As a result, each of the four modules was broken down into smaller pieces. For example, Module 2 was delivered in four parts. (See Table 2.) 
Table 2

Module 2, Structure

\begin{tabular}{llll} 
Part & $\begin{array}{l}\text { Capstone Activity at } \\
\text { End of Each Section }\end{array}$ & \multicolumn{1}{c}{ Skills Covered/Badges Earned } \\
1 & Millionaire Activity & $\begin{array}{c}\text { Instructor Feedback } \\
\text { Provided }\end{array}$ & Using positive constructions \\
& - Verb usage & No \\
& - Linking verbs & \\
2 & Notebook Task & - Active versus passive voice & Yes \\
3 & Dinger Shot Activity & - Paragraph structure & No \\
4 & Notebook Task & - Known-to-New, sentence formation & Yes \\
& & - Advanced paragraph structuring \\
& & \\
& &
\end{tabular}

To maximize flexibility for instructors, Scribe Hero was designed with various feedback options. Within the context of the LMS, instructors were given the opportunity to provide as much written commentary as they wished on notebook materials uploaded by students. Instructors also had the opportunity to assign badges based upon student performance on end-of-module notebook exercises. The badges had no in-course value but were there to incentivise student engagement with the notebook tasks. Instructors were given five different badge levels from which to choose: needs improvement, bronze, silver, gold, or platinum. Elsewhere, badges were designed and programmed for automatic release based on Shareable Content Object Reference Model (SCORM) reported data (i.e., performance on quizzes and completion of given modules). Instructors could track student performance based upon badge acquisition. Also, badges were designed to stress inclusivity. For example, the badge for excellence for Module 2, Part 4 was named after Misty Copeland, the first African American female principal dancer with the American Ballet Theatre (see figure 1).

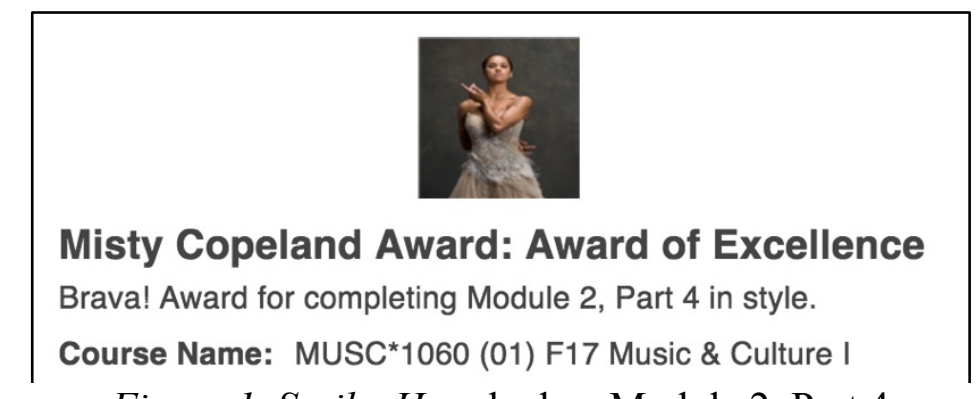

Figure 1. Scribe Hero badge, Module 2, Part 4

The intention was to have progression through the game be automated, with modules triggered by SCORM reporting. Unfortunately, an update to the University of Guelph's LMS two weeks prior to the beginning of the Scribe Hero project rendered SCORM reporting nonfunctional. Instead, the team chose to date release modules, meaning game flow was controlled by calendar date and not by student performance. Thus, the completion of a given challenge did not generate automatic badges, nor did it unlock subsequent portions of the online modules as had been envisioned. A more robust discussion of how this technical shortcoming affected the implementation of the online learning experience will follow in the results section of this paper. 
Scribe Hero was developed from September 2016 - August 2017 with sound engineering completed during the summer of 2017. User testing was conducted throughout by research assistants, who were responsible for testing the effectiveness of the modules, commenting on the level of challenge, and troubleshooting the stability of the online environment

\section{Methods}

This research study used a mixed-methods approach. Students completed pre- and postquizzes using Qualtrics to provide quantitative data. These Qualtrics quizzes were designed to assess students' basic knowledge of the content prior to completing the modules (pre-test) as well as the acquisition of learning outcomes after students participated in each module (post-test). The quizzes were accessed via a widget on the LMS homepage for each course. Students were given a week to complete the pre- and post-quizzes, with pre-quizzes released before students had access to the online modules and post-quizzes released after access to the corresponding Scribe Hero module had closed. Students were asked to provide a self-assessment of their skills on modulespecific content and were then invited to complete a quiz to track their knowledge.

Qualitative data responses were gathered from user experience surveys administered following the completion of the online modules. In the survey, students were asked a series of open-ended questions aimed at eliciting their perspectives and insights about their online learning experience of the Scribe Hero modules. (See Appendix 1.) Student responses were coded by hand and categorized manually by the study's PIs to identify patterns and ascertain primary themes. The researchers engaged in a process of emergent thematic coding, wherein they read the text several times to identify themes.

A purposeful sampling strategy was used to recruit participants for the study. Specifically, the research team reached out to professors who had previously incorporated workshops from the University Writing Centre into their courses. As mentioned earlier, we received positive responses from faculty who taught courses on Art History, Biology, Chemistry, Family Resources and Human Development, Music History, Psychology, Toxicology, and History. This population increased our potential student sample size to $n=1219$. The participation of diverse disciplines necessitated design changes to Module 3. We adapted the existing module's focus on the Chicago Manual of Style to accommodate an additional three style guides: American Psychological Association, American Society of Chemists, and Ecological Society of America.

All participants in this study were undergraduate students, though the open-ended nature of many of these courses meant that students enrolled were at all levels of study, from first to fourth year. This pool resulted in a range of students with a variety of disciplinary and personal backgrounds. To comply with Research Ethics Board (REB) guidelines, students were required to complete Scribe Hero as part of their course instruction; this component counted as 3 to $5 \%$ of their overall grade, depending on the instructor. Though obligated to complete the tool, students could opt out of having their data included in the study. All data presented here, therefore, appears with the consent of the participants. Approval was received to run the study, with all participating faculty agreeing that completion of the online modules (as opposed to performance on quiz content) would result in a final participation grade. The modules launched as part of the curriculum in these courses in the Fall 2017 semester. 
Researchers visited the participating classrooms to promote Scribe Hero during the first week of the semester and circulated additional emails and announcements through the LMS system to promote the study. A research assistant tracked student completion data over the course of the semester to provide grades to the students, but all subsequent data used by the research team was anonymized.

Due to the failure of the automated features of the modules, different professors chose to integrate Scribe Hero in different ways. For some instructors, monitoring submissions to the LMS and asking teaching assistants to provide feedback on those submissions was understandably too work-intensive, and therefore this feature of the modules was abandoned in certain courses. In fact, the music history classes were the only environments where students received feedback on endof-module submissions along with badges based upon completion of module content. While on the one hand, these methodological variations introduced confounding factors, these changes also inadvertently generated an intriguing data set that allowed us to explore the roles of feedback in the online learning experience. Our results then draw upon mixed methods, reporting first on the quantitative data generated from the Qualtrics quiz scores, followed by the responses captured through qualitative data in the form of a post-game user-experience survey.

\section{Results}

\section{Quantitative Data: In What Ways, if Any, Did Quantitative Test Scores Change Following the Introduction of Online Learning Modules?}

Our analysis of quantitative data was limited by the low number of participants in some of the classes selected. To satisfy basic statistical requirements, only courses with sufficiently high (n> 15) sample sizes were included. (See Table 3.)

Table 3

Participants Involved in the Research Study Broken Down by Course

\begin{tabular}{|c|c|c|c|c|}
\hline Subject & $\begin{array}{l}\text { Course } \\
\text { Number in } \\
\text { Analysis }\end{array}$ & $\begin{array}{l}\text { Overall } \\
\text { Course } \\
\text { Enrolment }\end{array}$ & $\begin{array}{l}\text { Participants } \\
\text { (Module 1) }\end{array}$ & $\begin{array}{l}\text { Participants who } \\
\text { completed all } 4 \\
\text { modules }\end{array}$ \\
\hline Art History & $\mathrm{N} / \mathrm{A}$ & 120 & 23 & $>15$ \\
\hline Biology & Course 1 & 356 & 182 & 131 \\
\hline Chemistry & $\mathrm{N} / \mathrm{A}$ & 49 & 26 & $>15$ \\
\hline $\begin{array}{l}\text { Family Resources } \\
\text { and Human } \\
\text { Development }\end{array}$ & Course 2 & 377 & 224 & 175 \\
\hline History & $\mathrm{N} / \mathrm{A}$ & 20 & 11 & $>15$ \\
\hline $\begin{array}{l}\text { Music History - } \\
\text { First Year }\end{array}$ & Course 3 & 87 & 59 & 36 \\
\hline $\begin{array}{l}\text { Music History - } \\
\text { Second Year }\end{array}$ & $\mathrm{N} / \mathrm{A}$ & 20 & 20 & $>15$ \\
\hline Psychology & Course 4 & 176 & 76 & 49 \\
\hline Toxicology & Course 5 & 50 & 27 & 29 \\
\hline
\end{tabular}


The quantitative data captured through comparison of Qualtrics pre- and post-quiz performance speaks directly to research questions 1 and 2, allowing us to track both student skill acquisition controlling for variations in students' basic level of knowledge at pre-test, as well as providing one way of viewing how variations in classroom use of the online modules may have been reflected in Qualtrics scores. Given the size of the participating population, the design did not include a true control group. That said, our analysis of the data does include different conditions that are compared to one another, thus providing a non-equivalent design without a control group. Module 3, which focused on citation skills, tested different types of content, because citation format in some disciplines differs significantly from others. In light of this variation in style, we decided that comparing data from this module would not provide a fruitful comparison. The data for Module 3, therefore, will not be considered in this paper. Because Modules 1, 2, and 4 tested similar content across all courses, we present the data pulled from Qualtrics quizzes relating to those modules here.

For Module 1, an analysis of covariance (ANCOVA) was conducted, examining post-test score differences across the five courses while controlling for pre-test individual differences of students' knowledge prior to completing the module. There was a statistically significant effect of pre-test scores on post-test scores $(F 1,562)=232.277, p<0.001)$, which supported our decision to control for pre-test scores in our analysis. The ANCOVA also identified a significant difference in performance at post-test across all five courses $(F 4,562)=5.391, p<0.001)$ A Bonferroni post hoc test revealed that post-test scores were statistically significantly higher for Course 1 (53.496 $\pm 0.499, p<0.001)$ compared to Course $2(50.694 \pm 0.450, p<0.001)$ after adjusting for pre-test scores. No other discrepancies were detected (see figure 2).

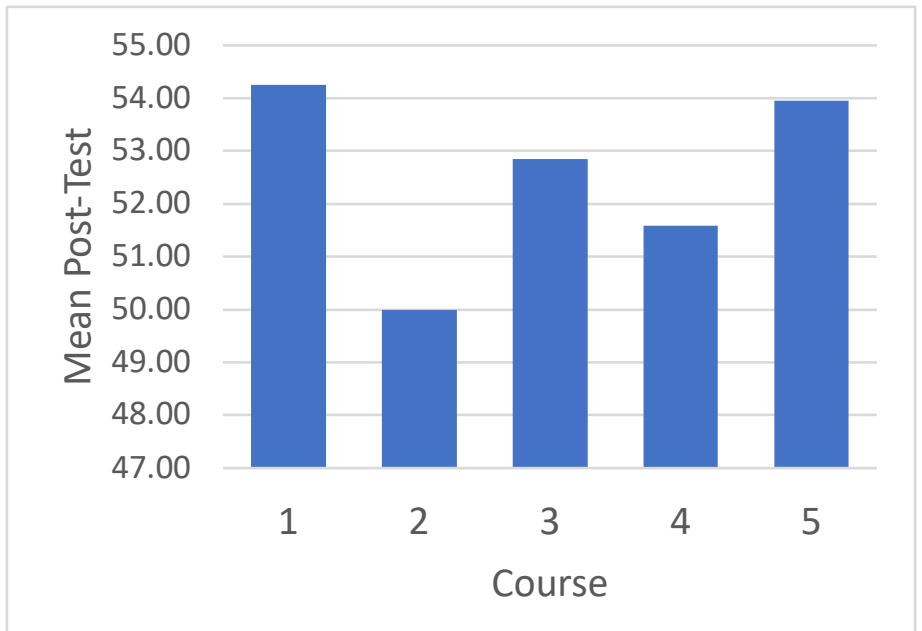

Figure 2. Comparison of mean test scores by course, controlling for pre-test scores, Module 1

A similar one-way ANCOVA was conducted on Module 2 to test post-test score differences across the five courses after covarying pre-test scores. Again, as expected, pre-test scores were significantly associated with post-test performance with students who had more prior knowledge performing better at post-test $(F 1,388)=232.723, p<0.001)$. The ANCOVA controlling for pre-test scores revealed that all courses improved from pre- to post-tests, with significant differences in post-test performance across some of the courses $(F 4,388)=6.789, p<$ 0.001). Bonferroni post hoc test showed that the mean post-scores for Course $3(25.349 \pm 0.953$, 
$p<0.05)$ were statistically significantly higher than the post-score means for Course $1(21.499 \pm$ $0.499, p<0.01), 2(20.205 \pm 0.414, p<0.001)$, and Course $4(20.703 \pm 0.740, p<0.001)$ (see Figure 3).

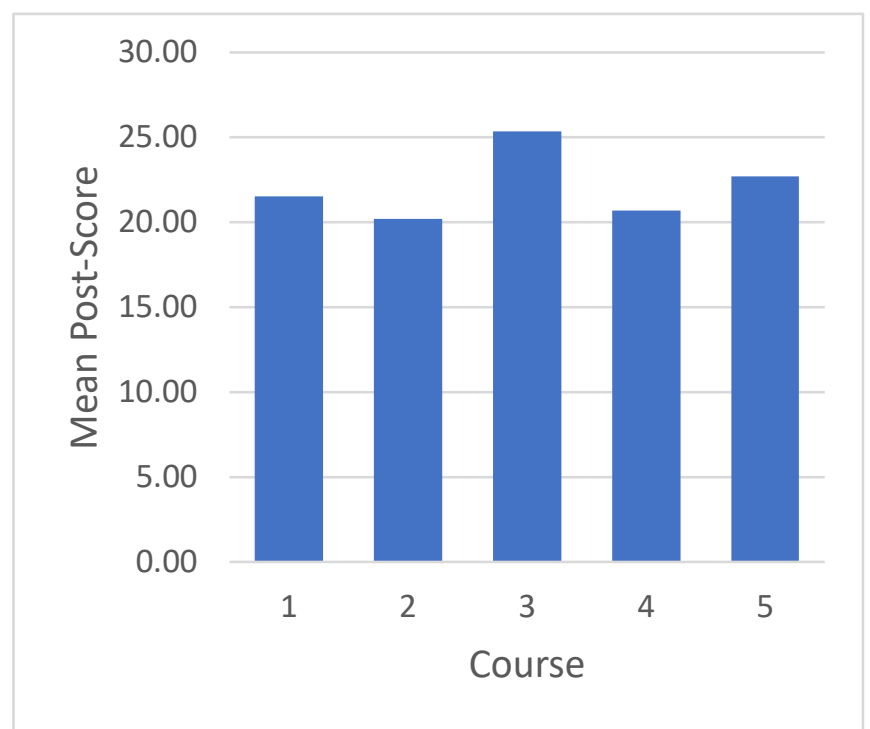

Figure 3. Comparison of mean test scores by course, controlling for pre-test scores, Module 2

For Module 4, a final ANCOVA was conducted using performance data on Module 4. This analysis again revealed that pre-test scores were predictive of post-test scores $(F 1,414)=447.207$, $p<0.001)$ as those with more prior knowledge performed better at post-test. After covarying pretest scores, post-score means were shown to differ across the courses $(F 4,414)=6.436, p<0.001)$. Post-test scores for Course $3(32.218 \pm 0.936, p<0.001)$ were statistically higher than those for Course $1(28.138 \pm 0.491, p<0.001), 2(27.341 \pm 0.42, p<0.001)$, and Course $4(26.859 \pm 0.802$, $p<0.001)$. Ultimately, though the analysis suggested that all courses had an impact on post-test scores, this effect was associated only with the performance improvement for Course 3, which outperformed those of the other classes in Modules 2 and 4 (see figure 4).

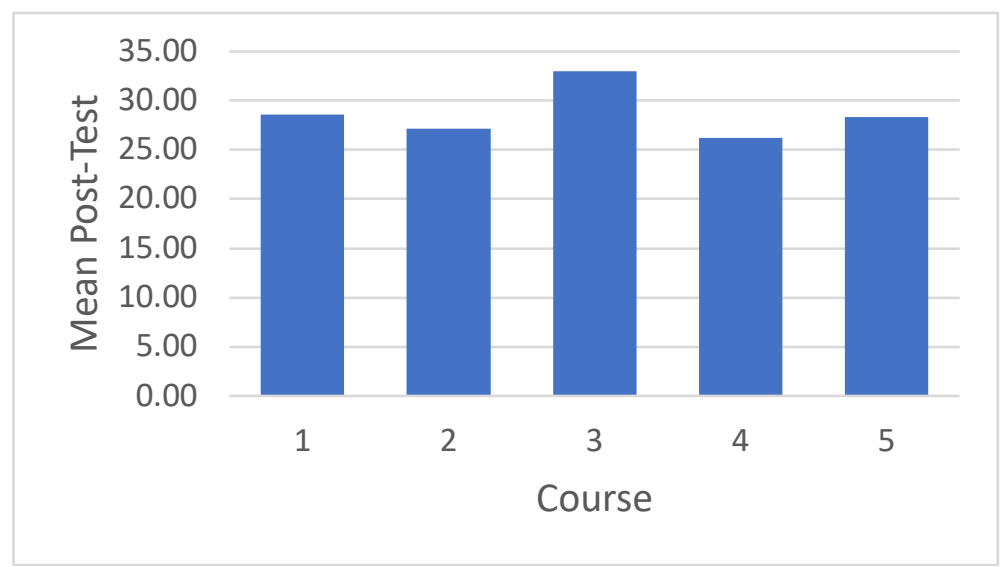

Figure 4. Comparison of mean test scores by course, controlling for pre-test scores, Module 4 


\section{Qualitative Summaries from the User Experience Surveys}

\section{What Were Students' Perceptions of the Online Learning Experience?}

Students from all classes were invited to participate in the user survey after access to the online modules had closed. This condition also meant that students who did not complete any part of Scribe Hero could contribute comments, and some did so to justify their reasons for refusing to engage with the tool. Students were asked to report on aspects of their online learning experience that they deemed relevant or useful and to provide feedback about the ways in which the modules could be improved.

Overall, we received 232 responses to the user experience survey with answers submitted by students from all participating classes. Overwhelmingly, when asked which parts of the modules they enjoyed, 50\% (146/292) of respondents identified Scribe Hero's instructional games as enjoyable, and 23.63\% (29/292) identified the instructional videos as enjoyable. An additional 61 students responded when asked to identify which portions of the modules they did not enjoy. In other words, students were far more inclined to identify things they did not like than those they did like. For this question, 41.32\% (150/363) of students identified the end-of-module notebook exercises and 32.51\% (118/353) of students selected the narrative videos as particularly unenjoyable. When asked about level of difficulty, students were fairly uniform in their responses with $84 \%$ of students responding that module content was moderately easy to neither easy nor hard, and $78 \%$ of students expressed that writing exercises were moderately easy to neither easy nor hard. As far as subject-matter was concerned, students were evenly split about which subjects they would like to see covered in further detail, with "None, the subject matter was covered enough" receiving slightly more votes with $24.32 \%$ of student responses (72/296). At the conclusion of the survey, students were provided space to elaborate on their ideas through prose comments. 102 respondents provided commentary. These comments were grouped thematically by the authors, with an eye to isolating trends in feedback.

The first qualitative theme that emerged from the data involved elements of the online learning experience that students found engaging and effective. Several students spoke positively about the instructional activities and the instructional videos found in the online modules. From the open-ended responses gathered, students characterized their learning experiences as "enjoyable," "a fun change of pace," and "a fun break from other assignments." One student wrote of Scribe Hero that it was a "breath of fresh air [from] the suffocating stress of my other assignments" and other students reported that they appreciated the chance to practice their writing, stating "I now feel that I have better writing skills for sure," and that the "[experience] taught me a lot about scientific writing!" Another student wrote that the modules were "actually more helpful than I thought it would be." When asked about specific subject matter, students generally agreed that the pedagogical material had been covered enough. Only one student identified a specific concept - passive voice - as something that should have been covered in further detail. Another student identified that they "learned a lot, especially about citations." Many commented that modules helped them to improve their grammar.

A second theme revealed students' self-reflection on how Scribe Hero might fit into their university studies more globally. For example, students wrote that the experience "really made me realise that I am not as solid as I thought I was with writing," and that it was "much preferred over writing an essay." Two students responded that the online modules should be assigned to all incoming first-year students in some capacity, one even commenting that "I think something like 
this should be [administered] to all incoming students during their summer before starting their first year." This student noted that providing these modules to students before they arrived on campus would give them time to self-select if they needed reinforcement of these skills and give them the opportunity to complete the material on their own time, outside of the stresses of coursework.

A third theme highlighted the long-term benefits of the experience and the transferability of the subject matter. For example, one student noted, "I think it has helped me a lot so far, and I found myself referring to it a lot when doing my final project" while another pointed out that, "overall, I found the [note]book the most helpful because I can look back on it when I need reminders on the subjects." Another student reported that Scribe Hero was "very helpful when writing paper [sic] such as literature reviews." Another student responded that "I think a lot of the information that was taught on [Scribe Hero] is very beneficial for the rest of my undergrad as well as for my career."

\section{Challenges and Areas for Improvement}

Several students spoke of the challenges and areas for improvement within the online learning environment. The first area identified by students were the end-of-module notebook exercises. One student reported, "the writing exercises were good, but I found it time consuming... If there was a quicker way...it would be much easier." Another student wrote that the notebook was too "difficult" to work with, another that it was not very "interesting." Two students requested the notebook be delivered as a word processable document, rather than a formfillable pdf, to make it more user-friendly.

A large number of students also discussed the integration and tone of narrative content across the online modules. Several students suggested an improvement to the paraprofessional premise presented through the cut-screen narrative videos. Some reported that the videos and final writing exercises "needed to be more seamlessly integrated" while other students suggested eliminating the narrative content altogether, claiming that it detracted from the effectiveness of the modules. Additionally, students were displeased with the tone in the videos. There were those who were critical of it, commenting, for example, that "the videos were a little childish," and "the tone of the videos seemed appropriate[sic] for early high school students, not really university level." Other students identified the narrative tone as detracting from their investment in the modules, writing "it felt way too childish and because of this ultimately made me unmotivated to complete the modules," and "it was condescending/demeaning." Overall, the majority of students who completed the survey indicated that the video content was not well targeted to a university audience - despite being instructionally sound, the storyline often seemed silly.

A final theme identified by students involved a desire for more feedback and for more personalised control over their progress through the game. Several students requested feedback be provided directly to them in the context of the online environment in real time. They wrote, "there were no signs of where you go wrong on games, and you just have to keep guessing until the next level pops up." Other students requested "a mark to see how well we have done" be embedded into the module itself, while another student suggested a "tracking system" or checklist be inserted that would allow students to self-monitor progress. Several students suggested the material would have been more engaging had they been able to complete material at their own pace. One reported that he should be able to "start or complete all modules at any time." Another wrote that the options for the modules should be "more diverse." Another responded that "the set up" did not allow 
students to "complete the game when they had free time," meaning the date-dependent delivery of the modules forced students to engage with Scribe Hero when other assignments, tests, and exams were the higher priority.

\section{Discussion}

The quantitative data indicates that students' acquisition of writing skills was enhanced following their interaction with the online learning modules. For those students who chose to complete all four modules, there was a consistent improvement in post-test scores across Modules 1,2 , and 4, regardless of which course they were enrolled in, suggesting that their grasp of writing skills improved. It is also possible that this improvement was the result of an increased emphasis on writing skills brought about by the implementation of the Scribe Hero modules in the course, or as a direct result of the testing effect. In other words, testing students on writing skills may have in and of itself made them more aware of, and more focused on, those elements between pre- and post-quizzes. Though we cannot say definitively whether or not students would have improved without Scribe Hero, the fact that they improved significantly in some courses more than others suggests that certain implementations of the online modules were more effective than others. For example, students in Course 3 received specific, frequent, and timely comments on their online submissions from their instructor, while the other classes did not. Also, students in Course 3 were the only group in this study to receive badges directly related to the quality of their submissions. This group showed a significantly higher rate of improvement in scores overall compared to the other classes sampled, suggesting that the intervention, when used with full functionality (including feedback and badges) was far more efficacious than the altered versions of the tool. Also, several students' reflections in the user experience survey connected their increased skill level with the content taught in the online learning modules, suggesting Scribe Hero played a role in improving some students' knowledge of writer's craft.

The results from Course 3 suggest that feedback incentivised learning throughout the process and resulted in improved engagement on the part of students. Indeed, despite the moderate autonomy provided by the online learning experience, students from across the study still articulated their desire for feedback of some kind. The students' comments emphasised their interest in knowing how they performed on a given task in real time, as well as their desire to have a clear sense of their overall progression through the material. Therefore, feedback is important to student engagement in an online learning environment, thus presenting a significant challenge when teaching writing to larger classes. If approaches such as Scribe Hero are to be useful to instructors of large classes - one of the primary goals of design - then finding a way to generate automatic yet meaningful feedback will be essential both for professor uptake and for student performance.

Scribe Hero, then, represented a diversion for some students and an opportunity to learn while "having fun." For others, certain aspects of the Scribe Hero experience were not enjoyable, running contrary to the team's assumptions. For example, the opposition to the arts-based scenarios and to the design of the modules in general meant that some students dropped out of the study or were less receptive to the lessons delivered. Indeed, the greatest complaints seemed to focus less on the pedagogical materials and more on the manner in which they were delivered, suggesting that graphics, sound engineering, and immersive elements such as narrative are essential in designing online modules for the discerning post-secondary student. Setting the correct tone, 
especially, requires that the material strike a balance between being fun and engaging, while still being challenging but not overwhelming. When introducing material through the online environment, questions of the sophistication of the delivery mechanism must be taken into serious consideration. Based upon student reports, if the technology or the online learning environment does not live up to expectations, it can create barriers to student learning.

The suggestion by students for further customisability seems to be a fruitful path forward. Allowing students the opportunity to progress at their own pace or having some sort of competency-based design would certainly enhance this type of approach. Fundamental to our future plans will be ensuring the dependability of the modules and the usability of design, but also the value and significance of building the modules in a manner whereby the pedagogy drives the technology and not the other way around. Designing the online experience with a focus on learning outcomes will help to facilitate a process of curating and selecting appropriate tools, processes, and strategies for use within the modules, structures that will be essential for any large-scale application of this sort of online learning template. Though the team considered these elements during the development phase for Scribe Hero, budget limitations and access to skilled personnel greatly curtailed the extent to which material could be developed. These lines of decision making can and will be a primary focus for future development.

\section{Conclusions}

Our research study, which ultimately served as a pilot project, indicates that undergraduate students' writing skills improved as a result of engaging in the online modules. Additionally, the results of this project suggest that many students both appreciated and enjoyed the flexibility and format of online learning as a means for developing writing skills that are essential to success in most, if not all, undergraduate courses. The data revealed that many students enjoyed the gamebased elements and videos embedded in the modules. These findings, therefore, suggest that homing in on further online methods and approaches to teach writing skills will be an important and interesting avenue to consider in future development.

Another important consideration moving forward is that the teaching and learning experience of these online modules was enhanced through the periodic insertion of formative instructor feedback. Automation of some of this feedback will be necessary for wide-spread uptake of this sort of technology by instructors, whilst maintaining a feel of customization for the learner. Also, additional technological tools and approaches will be explored in subsequent design and development to find a more effective and integrated solution. In some cases, the technology impeded rather than enhanced or supported the learning, which is an area that warrants further investigation prior to any (re)development.

Overall, participants identified three key aspects for an effective online learning experience: the incorporation of competency-based elements, the compatibility and user-friendly nature of the technology, and the direct applicability of taught skills rather than remedial writing instruction. This small-scale research project provides us with some evidence to build on in future design, development, and delivery, and it offers many lessons that can be transferred to other undergraduate classrooms cases, in particular music and arts-focused spaces. 


\section{Acknowledgement}

This project was funded by various bodies at the University of Guelph, including the Learning Enhancement Fund (Office of the VP Academic), the THINC Lab, and the College of Arts. The team would like to thank Tara Abraham, Christina Caruso, Harjinder Gill, Sally Hickson, Martina Meyer, Robin Milhausen, and Kate Stuttaford. The team is grateful to Sarah Gibbons from Writing Services for her contributions to the editing of pre- and post-quiz questions, and we would also like to acknowledge the creative contributions of Anneliese Belder, Stephanie Berec, Aaron Bowlby, Alexandra Gasbarrino, Ryan Maxwell, Sarah Gibbons, Jack McCart, Tom Beggs, Claudia Barned, Athol Gow, Rob Kerr, and everyone who lent their voice talents to the Scribe Hero instructional videos. The authors would like to thank the Educational Development Team at the University of Guelph, especially Claire Coulter, Aron Fazekas, and Owen Wooding, and a special thanks is due to the students who participated in this study. 


\section{References}

All, A., Castellar, E., \& Looy, J. (2016). Assessing the effectiveness of digital game-based learning: Best practices. Computers \& Education, 92-93, 90-103.

Antonius, D., Brown, A.D., Todman, M., \& Safran, J. (2007). Integrating science in applied psychology programs: A student-operated journal. Teaching of Psychology, 34 (1), 31-34.

Barab, S. A., Arici, A., \& Jackson, C. (2005). Eat your vegetables and do your homework: A design-based investigation of enjoyment and meaning in learning. Educational Technology, 65(1), 15-21.

Barab,S., Peetyjohn, P., Gresalfi, M., Volk, C., \& Solomou, M. (2012). Game-based curriculum and transformational play: Designing to meaningfully positioning person, content, and context. Computers and Education, 1 (58), 518-533.

Bates, T. (2017). Results from the Canadian survey of online learning now available. Retrieved from: https://www.tonybates.ca/2017/10/19/results-from-the-canadian-survey-of-onlinelearning-now-available/.

Bean, J. (2011). Engaging Ideas: The Professor's Guide to Integrating Writing, Critical Thinking, and Active Learning in the Classroom ( $2^{\text {nd }}$ ed.). San Francisco, CA: Jossey Bass.

Blummer, B., \& Kritskaya, O. (2009). Best practices for creating an online tutorial: A literature review. Journal of Web Librarianship, 3 (3), 199-216.

Burke, A. (2010). Teacher as leader in a 'flat world:' Preparing students in a global community. Language Arts Journal of Michigan, 25 (2), article 4.

Carter, M. (2003). A process for establishing outcomes-based assessment plans for writing and speaking in the disciplines. Language and Learning Across the Disciplines, 6 (1), 4-28.

Carter, M. (2007). Ways of knowing, doing, and writing in the disciplines. College Composition and Communication, 58 (3), 385-418.

Condon, W., \& Kelley-Riley, D. (2004). Assessing and teaching what we value: The relationship between college-level writing and critical thinking abilities. Assessing Writing, 9, 56-75.

Dalton, J. P. (2000). Online Training Needs a New Course: The Forrester Report. Cambridge: Forrester.

de Freitas, S. (2016). Learning in immersive worlds: A review of game-based learning. JISC elearning program. Bristol: Joint Information Systems Committee.

http://www.jisc.ac.uk/media/documents/programmes/elearninginnovation/gamingr eport_v3.pdf

Erhel, S., \& Jamet, E. (2013). Digital game-based learning: Impact of instructions and feedback on motivation and learning effectiveness. Computers \& Education, 67, 156-167.

Gammill, D. (2006). Learning the write way. The Reading Teacher, 59 (8), 754-762.

Graham, S. (2006). Strategy instruction and the teaching of writing: A meta-analysis. In C. A. MacArthur, S. Graham, \& J. Fitzgerald (Eds.), Handbook of Writing Research (pp. 187207). New York: Guilford Press. 
Gresty, K. A., \& Edwards-Jones, A. (2012). Experiencing research-informed teaching from the student perspective: Insights from developing an undergraduate e-journal. British Journal of Educational Technology, 43 (1), 153-162.

Hamari, J., Shernoff, D., Rowe, E., Coller, B., Asbell-Clarke, J., \& Edwards, T. (2016). Challenging games help students learn: An empirical study on engagement, flow and immersion in game-based learning. Computers in Human Behavior, 54, 170-179.

Heuer, B. P., \& King, K. P. (2004). Leading the band: The role of the instructor in online learning for educators. The Journal of Interactive Online Learning, 3 (1), 1-11.

Jalongo, M. R. (2007). Beyond Benchmarks and Scores: Reasserting the Role of Motivation and Interest in Children's Academic Achievement. Association for Childhood Education International, 83 (6), 395-407.

Pace, D. (2017) The Decoding the Disciplines Paradigm: Seven Steps to Increased Student Learning. Bloomington: Indiana University Press.

Qian, M., \& Clark, K. (2016). Game-based learning and $21^{\text {st }}$-century skills: A review of recent research. Computers in Human Behavior 63, 50-58.

Reimers, F. M. (2008). Preparing students for the flat world. Education Week 8.

Rigby, S., \& Ryan, R. (2007). The player experience of need satisfaction (PENS): An applied model and methodology for understanding key components of the player experience. Retrieved from http://immersyve.com/white-paper-the-player-experience-of-needsatisfaction-pens-2007/

Zeni, P., White, D., Wilson, K., \& Troop, M. (2018, June). UX Design for Learning: An evidence-informed approach to online course design. Presentation at the STLHE Congress, Sherbrooke, QC.

Zhao, N., \& Wardeska, J. G. (2011). Mini-journal inquiry laboratory: A case study in a general chemistry kinetics experiment. Journal of Chemical Education, 88 (4), 452-456. 


\section{Appendix I}

\section{Open-Ended User Experience Survey Questions:}

Q1 Which of the following parts of Scribe Hero did you enjoy?
a) The narrative videos
b) The instructional videos
c) The instructional games
d) Notebook exercises

Q2 Which of the following parts of Scribe Hero did you not enjoy?
a) The narrative videos
b) The instructional videos
c) The instructional games
d) Notebook exercises

Q3 How easy would you say the instructional games in Scribe Hero were?
a) Too easy
b) Moderately easy
c) Neither easy nor difficult
d) Moderately difficult
e) Too difficult

Q4 How easy would you say the writing exercises in Scribe Hero were?
a) Too easy
b) Moderately easy
c) Neither easy nor difficult
d) Moderately difficult
e) Too difficult

Q5 Which subjects from Scribe Hero would you like to see explained more?
a) None, the subject matter was covered enough.
b) Part on descriptive vs. analytical prose
c) Part on passive voice
d) Part on citation
e) Part on grammar

Q6 Which part(s) from Scribe Hero did you like the least?
a) Nothing, the game was well balanced.
b) Part on descriptive vs. analytical prose
c) Part on passive voice
d) Part on citation
e) Part on grammar
f) The notebook

Q7 Which of the following platforms/delivery systems would you prefer for Scribe Hero?

a) Embedded directly in your LMS

b) As an extension to the online textbook materials

c) As a stand-alone app

Q8 Anything else you'd care to share about your experience with Scribe Hero? 